\title{
QoE-aren optimizaziorako indize-erregelen proposamenak sare-baliabideen esleipenerako planifikazioan
}

\author{
Ianire Taboada* \\ Adierazpen Grafikoa eta Proiektuak Saila, eta Komunikazioen Ingeniaritza Saila \\ (UPV/EHU) \\ Fidel Liberal \\ Komunikazioen Ingeniaritza Saila \\ (UPV/EHU) \\ *ianire.taboada@ehu.es
}

DOI: 10.1387/ekaia.14384

Jasoa: 2015-04-28

Onartua: 2015-09-02

Laburpena: Lan honetan sakon aztertu dira erabiltzaileek hautemandako kalitatearen maximizazioa helburu duen sare-baliabideen planifikaziorako scheduling algoritmoak, beti ere sare-baliabideen esleipenean kalitate subjektiboaren maximizaziorako planifikazioaren garrantzia eta beharra buruan izanda. Ikerketak bereziki erreparatu dio matematika arloan ekarpen handia egin duten Gittins zein Whittle metodoen bidez lortutako kalitate subjektiboaren maximizaziorako scheduling indize-erregela motako soluzioen azterketei. Modu honetan, lehenik eta behin, bi diziplina horiek aurkeztu dira, Gittinsena bakunagoa izanik. Ondoren, bi planifikazio-politika horien errendimenduak elkarrekin erkatu dira, eta ikusi da Whittlen-en konponbideak emaitza nabarmenki hobeak erakusten dituela. Ondorioz, Gittins edo Whittle metodoetan oinarritutako proposamena aukeratuko da.

Hitz gakoak: planifikazio-algoritmoa, hautemandako kalitatea, indize-erregela, Gittins indizea, Whittle indizea.

Abstract: Considering the importance and necessity of network resource allocation for maximizing subjective quality, this work deals with scheduling algorithms aimed at maximizing users' perception of quality. This research is focused on the analysis of subjective quality aware scheduling index rule solutions obtained by means of Gittins and Whittle methods, which have a great contribution in the mathematics area. In this way, first of all, we present the previous disciplines, being the Gittins-based simpler. Then, we compare the performance of these scheduling policies, showing that the Whittle-based solution gives considerably better results. As a conclusion, a tradeoff be- 
tween the index complexity and the achievable subjective quality exists, when choosing the Gittins-based or the Whittle-based proposal.

Keywords: scheduling algorithm, quality of experience, index rule, Gittins index, Whittle index.

\section{SARRERA}

Ezbairik gabe, Internet behar-beharrezkoa bilakatu da eguneroko bizitzan, eta horrek datu-sareen erabilera masiboa ekarri du, bereziki sare mugikorren erabilera masiboa. Web edo multimedia bezalako Internetaplikazioen erabileraren igoera horrek sareko banda zabalera eskaeraren hazkundea eragin du. Beraz, oso garrantzitsua da bukaerako erabiltzaileak zerbitzuaren kalitatean hornitzeko sare baliabideen partekatze eta erabilera eraginkorra izatea.

Nahiz eta telekomunikazio estandarrek zerbitzuaren kalitatea kontuan hartzen duten arkitekturak definitu [1-2], ez dute sare baliabideen kudeaketarako planifikazio-estrategia espezifikorik zehazten. Beraz, funtsezkoa da errendimendu egokia bermatzeko planifikazio-algoritmoen diseinu egokia egitea.

Tradizionalki, sare baliabideen esleipena atzerapena, abiadura edo paketeen galera bezalako sare-parametro objektiboetara bideratzen da, bukaerako erabiltzaileen benetako asetzea alde batera utziz. Hala ere, erabiltzaileen asebetetzean oinarritutako baliabideen esleipen ikuspegi hori ezinbestekoa da, eta sare operadoreek zein hornitzaileek motibazio argia dute euren bezeroen gogobetetzea lortzeko. Horrela, lan honetan, erabiltzaileak hautemandako kalitatea optimizatzen duten planifikazio algoritmoak aztertzeari ekingo zaio.

\subsection{Aurrekariak}

Planifikazio-algoritmoak optimizazio problema bezala egokiro formula daitezke. Gainera, planifikatzailea kontrolatzaile modura ikus daiteke. Modu honetan, kontrol-akzioa aukeratuko den erabiltzailea zehaztean datza.

Hortaz, planifikazio algoritmo horiek kontrol edo erabaki problema bezala formula daitezke. Ildo honetan, baliabide-esleipen estokastikoaren eta dinamikoaren problemak era naturalean modela daitezke Markoven-en Erabaki Prozesuen (MDP, Markov Decision Process) [3-4] izenekoaren barruan.

Edonola, matematikoki dotorea da MDP-an oinarritutako optimizazio ikuspegia, baina optimizazio problema errealen ebazpenerako kontrol pro- 
zesu markoviar horien erabilerak oso eragozpen larria du, zeren eta gehienetan ezin lor baitaitezke problema praktikoak ebazteko beharrezkoa den memoria prozesamendu-betekizunak [5-6].

Eragozpen hori gainditzeko, egokiagoa da baliabide-kudeaketa optimizazio problema MDP bezala formulatzea, eta ondoren, problema konplexu trataezinen soluziotzat azpioptimoa edota optimoa den heuristika erraza lortzea. Heuristika horien artean daude indize-erregela motako planifikazio-estrategiak [7-8]. Indize-erregela baten bidez, kalkulatu nahi izaten da zein den erabiltzaile bakoitzerako indize deitutako lehentasuna islatzen duen balioa, eta era honetan, planifikatzaileak indize altuena duen erabiltzailea aukeratuko du transmisio une bakoitzean.

Modu honetan, lagungarria suertatzen da planifikazio=eredu analitiko horien ebazpenerako lehentasunean oinarritutako indize-erregela motako soluzioak eskuratzea. Horrela problema horien ebazpena erraztu eta soluzio bakunak lortzen dira.

Zalantzarik gabe, gehien aztertutako baliabide esleipen problemek erabiltzaileen trafiko fluxuen batez besteko atzerapenaren minimizazioa dute helburu. Atzerapen horrek erreferentzia egiten dio tamaina finituko fluxu baten bit guztiak kanalera transmititzeko beharrezko denborari. Emaitza klasikoek adierazten dute fluxu laburrei lehentasuna emateak guztirako batez besteko atzerapena minimizatzen duela [9-10]; hau da, aldiuneko bukatze-probabilitate altuena duten fluxuak lehenesteak sistemaren bataz besteko atzerapena minimizatzen du. Dena dela, egungo IP sare-sistemetan ez da ohikoa fluxuen tamaina aurretik jakitea. Hori dela eta, badira non-anticipating edo aurreratu gabeak deitutako aurretik fluxuaren tamaina ez dakiten tamainan oinarritutako planifikazio-diziplinak [11]. Politika horiek tamaina-informazio modura erabiltzen dute fluxu batek unera arte kanalera transferitutako bit kopurua, attained service-a edo eskuratutako zerbitzua.

Arlo honetan lanik aipagarriena Gittins indize estrategia da [12-13]. Gittinsek batez besteko atzerapena minimizatzeko problema MDP plataforman formulatzen du. Era honetan, eskuratutako zerbitzua kontuan hartuta, atzerapenaren batezbestekoa minimizatzen duen indize-erregela sinplea proposatzen du, kanal kapazitatea konstantea denerako.

Bestalde, azken hamarkadan haririk gabeko edo wireless sistemetan emandako aurrerapen teknologikoek irrati-baliabide eskasen esleipenerako planifikazioaren interesa piztu dute erabiltzaileen artean. Haririk gabeko loturetan kanalaren kapazitatea aldatzen doa denboran zehar, ingurunea beraren degradazioen ondorioz, eta horrek denboran aldakorrak diren kanaletan planifikazio problemaren ikerketa bultzatu du. Channel-aware deitutako planifikatzaileak kanalaren kalitatean oinarritzen dira. Horien barruan, badaude opportunistic deituriko politikak, erabiltzailearen kanal-ka- 
litatea bere historialaren menpe ona den edo ez erabakitzen dutenak [14]. Literaturan zehar zenbait channel-aware estrategia aztertu dira, Max Rate eta Proportional Fair [15] ezagunenen artean. Hala ere, ezezaguna da denboran aldakorra den zerbitzu tasa duten ereduen soluzio optimoa lortzeko ebazpena.

[16-18] lanetan batez besteko atzerapenaren problema denboran aldakorra den kanalean MDP baten bidez formulatzen da, eredu horren osagaia erabiltzaileen aldiuneko kanal-egoera izanik. Bestalde, MDP-a analitikoki ebaztearen ezintasuna dela eta, hurbilketak erabiltzen dira. Azterketa hauetan, zorizko kanal-kapazitatearen kasurako, Whittle indize ikuspegiari jarraituz [19], kanal kalitatearen menpekoak diren eta optimotik hurbil dauden indize-erregelak lortzen dira.

Whittle metodoaren arabera optimizazio problema sinplifikatu daiteke une bakoitzean bataz beste $M$ erabiltzaile zerbitzatuz. Ondoren, erabiltzaile bakarreko salneurrian oinarritutako optimizazio problema parametrizatuan deskonposa daiteke, metodo lagrangiarrak erabilita [20]. Bai Gittins bai Whittle indizeak, erabiltzaile bakoitzerako era isolatuan kalkulatzen dira, beste erabiltzaileetatik beregain independenteki. Hala ere, Gittinsen esparruan ez bezala, erabiltzailea aukeratua ez bada, erabiltzaile bakoitzaren MDP ereduan egoera-aldaketak eta sari irabazpenak onartzen dira, restless deitutako problemen motakoa izanik; kanal aldakorreko ereduak mota honetakoak dira. Ezaugarri horrek Whittle indizea Gittins indizea orokortzea eragiten du, eta problema mota horietan, orohar, Whittle indizearen errendimendua hobea da Gittins indizearena baino.

Alabaina, zerbitzuaren kalitate-parametro objektibo ezberdinak helburu dituzten planifikazio=eskemak proposatu dira literaturan zehar baina, erabiltzaileak hautemandako kalitate subjektiboaren maximizazioa xede duten baliabideen esleipen-estrategiei ez zaie behar bezalako arreta jarri. Era honetan, agerian geratzen da oso beharrezkoa dela zerbitzuaren kalitate subjektiboaren maximizazioa ekarriko duen sare-baliabideen planifikazio estrategia bat.

Erabiltzaileak hautemandako kalitatea adierazteko QoE (Quality of Experience) terminoa halaxe definitzen du ITU-T-k [21]: «Bukaerako erabiltzaileak hautemandako zerbitzu edo aplikazio baten onargarritasun orokorra». [22-23] lanetan proposatzen dira QoE-a maximizatzea helburu duten indize-erregelen artean aipagarrienak. Lehenengoa, Gittins ikuspegian oinarritzen da, eta kanal konstanterako ebazten da. Bigarrenaren lorpenerako, berriz, Whittle metodoa erabiltzen da, denboran aldakorra den kanalaren kasurako. 


\subsection{Helburuak}

Agerian dago erkaketa bat egin behar dela QoE-aware planifkazio eremuan hain ekarpen handia egin duten bi proposamen horien [22-23] artean. Horixe izan du lan honek helburu nagusi.

Bestalde, ekitatearen kontura metrika baten optimizazioa lortzea alderdi aipagarria da, baliabideen kudeaketa-estrategiak diseinatzerakoan [24]. Planifikazio-algoritmo bat bidezkoa izan behar da honako zentzuan: metrika baten optimizazioa bermatzeaz gain, bermatu egin behar da banako fluxuak modu justuan tratatzen ote diren, erabiltzaile batzuek emaitza oso onak lortzea eta gainontzekoak zigortzea ekidinez. Aurreko QoE-aware indize-erregelen lanetan batez besteko QoE-a landu da soilik. Hortaz, aurreko bi planifikazio proposamen horien ekitatea hartuko da azpi-helburu bezala.

Gainontzeko artikulua horrela egituratuko da: 2. atalean erkatuko diren bi QoE-aware indize-erregelak deskribatzen dira. Gero, 3. atalean, bi politika horien errendimenduak elkarrekin erkatuko dira. Bukatzeko, 4. atalean, lan honen ondorio garrantzitsuenak laburbilduko dira.

\section{QoE-AWARE INDIZE-ERREGELEN DESKRIBAPENA}

Atal honetan, QoE-aren maximizaziorako planifikazio indize-erregelak deskribatuko dira. Erregela horiek, planifikazio arloan garrantzi handia izan duten metodo matematikoetan oinarria duten [22-23] lanetan proposatu dira.

Bestalde, erabiltzailearen asebetetzea batez besteko iritzi-kalifikazio (MOS, Mean Opinion Score) metrikaren bidez [25-26] eskala batean ebaluatzen da eskuarki, 1etik (kalitate oso eskasa) 5erako (kalitate bikaina). Era honetan, aztergai diren QoE-an oinarritutako politika horietan, erabiltzaile bakoitzeko QoE-a kuantifikatzen duen eta atzerapenaren menpekoa den MOS utilitate funtzioa erabiltzen da. Funtzio horretan hiru tarte bereiz ditzakegu: atzerapen balio baxu baten azpitiko kalitate maximoko atala, atzerapen balio altu baten gainetiko zerbitzu jasanezineko atala, eta aurreko bi atalen arteko QoE-aren degradazio atala.

Lehenik eta behin, Gittins metodoaren bidez lortutako QoE-aware indize-erregela aurkeztuko da, Gittins MOS (GM [22]) deitutakoa. Hurrengo azpi-atalean, Whittle metodoaren bidez eskuratutako Attained Service dependant Potential Improvement MOS (ASPIM [23]) politika azaltzen da.

\subsection{GM [22]}

GM proposamena Gittins metodoa erabilita ondorioztatu da. GM QoE-aware den eta fluxu tamainan oinarrituta dagoen planifikazio indize- 
erregela bat da. Horren indizearen balioa eskuratutako zerbitzuaren menpekoa den uneko bukatze-probabilitatearen eta atzerapenaren menpekoa den MOS funtzio normalizatuaren arteko biderkadura da. Hortaz, QoEaware politika horrek estatistikoki bukatzeko gertuago dauden fluxuei eta QoE degradazio gehiegirik jasan ez dutenei lehentasuna ematearen arteko oreka bilatzen du.

Horrez gain, lortutako konputazionalki tratagarria den adierazpenak, proposatutako indize-erregelaren inplementazio arina ahalbidetzen du edozein planifikazio logikatan.

\subsection{ASPIM [23]}

Beste alde batetik, kanal aldakorrean QoE-aware planifikazio proposamenari dagokionez, ASPIM erregela hori lortzeko Whittle metodoa erabili da.

ASPIM diziplina QoE-aware den, channel-aware den eta fluxu tamainan oinarritzen den indize-erregela tratagarria da. Kanal aldakorrerako lortutako QoE-aware diziplina horrek kanal onenean dauden eta kalitate subjektiboan saturaturik ez dauden erabiltzaileak lehenesten ditu. Kanalbaldintza kondizio onenean ASPIM indizea kanal konstanterako proposatutako GM indizearen baliokidea da. Gainontzeko kanaletan, berriz, indizearen balioa uneko bukatze-probabilitatearen eta MOS funtzioaren arteko biderkadura eta bukatze-probabilitatearen hobekuntzaren arteko ratioa da. Bukatze-probabilitatearen hobekuntza kanal-egoera probabilitateen menpekoa da.

\section{ERRENDIMENDUAREN ANALISIA}

Atal honetan proposatutako QoE-aware indize-erregelen errendimenduaren azterketa egiteari ekingo zaio. Horretarako, planifikazio-proposamenen errendimendua planifikazio- estrategia ospetsuekin alderatuko da simulazioen bitartez.

\subsection{Simulazioen ezaugarriak}

Azpi-atal honetan GM eta ASPIM planifikazio estrategien portaera aztertu eta erkatzeko egindako simulazioen parametro nagusiak aurkezten dira.

Aztertuko den konfigurazioak, benetako LTE wireless sare bateko agertokia islatzen du. Horretarako, sistema mailako irrati-sarbide simulagailu batetik [25] eskuratutako Kanalaren Kalitate Adierazle (CQI, Channel Quality Indicator) trazak erabili dira. CQI txosten hauek tresna mu- 
gikorretatik oinarri-estaziora bidaltzen dira, oinarri-estazioan dagoen planifikatzaileak erabiltzaile bakoitzaren kanal kapazitatea zein den jakiteko. Irrati-zelulan $5 \mathrm{~km} / \mathrm{h}$ abiaduran mugitzen diren erabiltzaileak hartzen dira kontuan. Kasu horretan, kanalaren propagazioa Extended Pedestrian A ereduaren bidez definitzen da. Gaur egungo LTE bezalako wireless teknologietan gertatzen den bezala, hamasei kanal-egoera erabiltzen dira. CQI horiei dagozkien transmisio-abiadurak, $r$, eta kanal-egoera probabilitateak, $q, 1$. taulan azaltzen dira. CQI altuenak ez dira aurkezten, haien egoera probabilitatea oso txikia baita.

1. taula. CQI bakoitzeko transmisio-abiadurak (r) eta kanal-egoera probabilitateak (q).

\begin{tabular}{llccccccccccc}
\hline \multicolumn{1}{c}{ CQI } & \multicolumn{1}{c}{0} & 1 & 2 & 3 & 4 & 5 & 6 & 7 & 8 & 9 & 10 & 11 \\
\hline $\mathrm{r}(\mathrm{Mbps})$ & 0 & 4,2 & 6,72 & 8,4 & 11,25 & 16,8 & 21,84 & 25,2 & 26,88 & 33,6 & 44,68 & 50,4 \\
$\mathrm{q}$ & 0,28 & 0,12 & 0,09 & 0,08 & 0,08 & 0,08 & 0,07 & 0,06 & 0,05 & 0,04 & 0,03 & 0,01 \\
\hline
\end{tabular}

Planifikatzaileari dagokionez, erabiltzaile bakarra zerbitzatzeko planifikazio-erabakiak $1 \mathrm{~ms}$-an behin egingo dira. Behean, QoE-aware indizeerregelez aparte, simulazioetan erabiliko diren planifikazio-algoritmoen deskribapena aurkezten da:

- Max Rate (MR) [15]: Channel-aware politika hau une bakoitzean aldiuneko kanal-kapazitate altuena duen erabiltzailea zerbitzatzean datza, sarearen transmisio tasa maximizatzeko asmoz.

- Proportional Fair (PF) [15]: Opportunistic motako diziplina honek aldiuneko transmisio tasa eta eskuratutako transmisio tasaren arteko ratio altuena duen erabiltzailea aukeratzen du.

Bestetik, berdinketak egotekotan, berdinketa haustea ausazko eran egingo da.

Bestalde, aztergai den agertoki honetan, fluxu-tamainan eta QoE ezaugarrian desberdintzen diren bi erabiltzaile klase aztertzen kontsideratzen dira. Sistemako trafiko fluxuei erreferentzia eginez, simulazioetan erabilitako fluxu tamaina banaketa Pareto da, klase bakoitzaren batez besteko tamainak $5 \mathrm{Mbit}$ eta $50 \mathrm{Mbit}$ izanik. Tamaina horiek gaur egungo haririk gabeko sareetan erabiltzen dira. QoE-ari dagokionez, lehenengo klasea QoE-an zorrotzagoa da, atzerapenaren behe eta goi atalaseak honakoak izanik: lehenengoarenak, $0,5 \mathrm{~s}$ eta $5 \mathrm{~s}$, eta bigarrenarenak, berriz, $5 \mathrm{~s}$ eta $30 \mathrm{~s}$. Kalitarearen degradazio tarterako funtzio logaritmikoa erabiltzen da. 
Bestalde, planifikazio estrategien portaera sare-kondizio ezberdinetan aztertzeko asmoz sare-kondizio ezberdinak aztertuko dira. Ikasketa honetan zazpi sare egoera dira: karga baxua ( $\varrho=0,25 ; 0,375)$, karga ertaina $(\varrho=0,5 ; 0,75)$ eta karga altua $(\varrho=0,85 ; 0,9 ; 0,95)$.

Sare baliabideen planifikaziorako sare-ingurunea Matlab erabilita inplementatu da. Planifikazio-diziplina eta sare-karga konbinazio bakoitzeko, 10.000 simulazio segundoko iraupena duten 10 simulazio txanda egingo dira. Txanda horiek ausaz sortutako tamaina zein heldueratan desberdintzen dira.

Gisa honetan, aztergai den metrika bakoitzaren batez besteko balioa 10 txandadun simulazio multzoan lortutako metriken batezbestekoa izango da guztirako. MOS lagin kopurua mugatuta dagoenez, aztertutako metrika bakoitzerako arentzat \%95eko konfidantza tarteak kalkulatuko dira T-test-aren bidez. Molde honetan, errendimenduaren azterketarako irudietan metrika horiei dagozkien \%95eko konfidantza tarteak sartuko dira.

\subsection{Emaitzak}

GM eta ASPIM indize-erregelak batez besteko MOS-a maximizatzeko helburuarekin proposatu dira, eta beraz, azterketarako errendimendu-metrika nagusia batez besteko MOS-a izango da. Gainera, batez besteko MOS-a aztertzeaz gain aparte, planifikazio-politiken ekitatea ikertuko da QoE-n. Ekitate neurri bezala MOS-aren Jain indizea [26] erabiliko da. Indize horren balioa 0tik 1erako tartean dabil, eta zenbat eta batetik gertuago, orduan eta justuago bidezkoagoa politika metrika horrekiko.

Batez besteko QoE-aren emaitzak 1. irudian biltzen dira. Ikus daitekeenez, ASPIM-en eta GM-en arteko aldea nabarmentzekoa da, bereziki @ altuentzat. Gainera, sare-karga altuenerako ere ASPIM-ek lortutako balioak 4-ren gainetik mantentzen dira. Horrez gain, MR-en eta PF-en batez besteko MOS-ak biziki baxuagoak dira.

2. irudian laburbiltzen dira QoE-aren ekitateari dagozkion emaitzak. ASPIM-ek ekitate maila egokiak lortzen ditu, MOS-aren Jain indizearen balioak 0,9ren gainetik mantentzen direlarik. GM-rekiko aldea 0,1 baino altuagoa da. Era berean, QoE-aren ekitatean, MR eta PF nabarmen-okerragoak dira. 
QoE-aren optimizaziorako indize-erregelen proposamenak sare-baliabideen esleipenerako planifikazioan

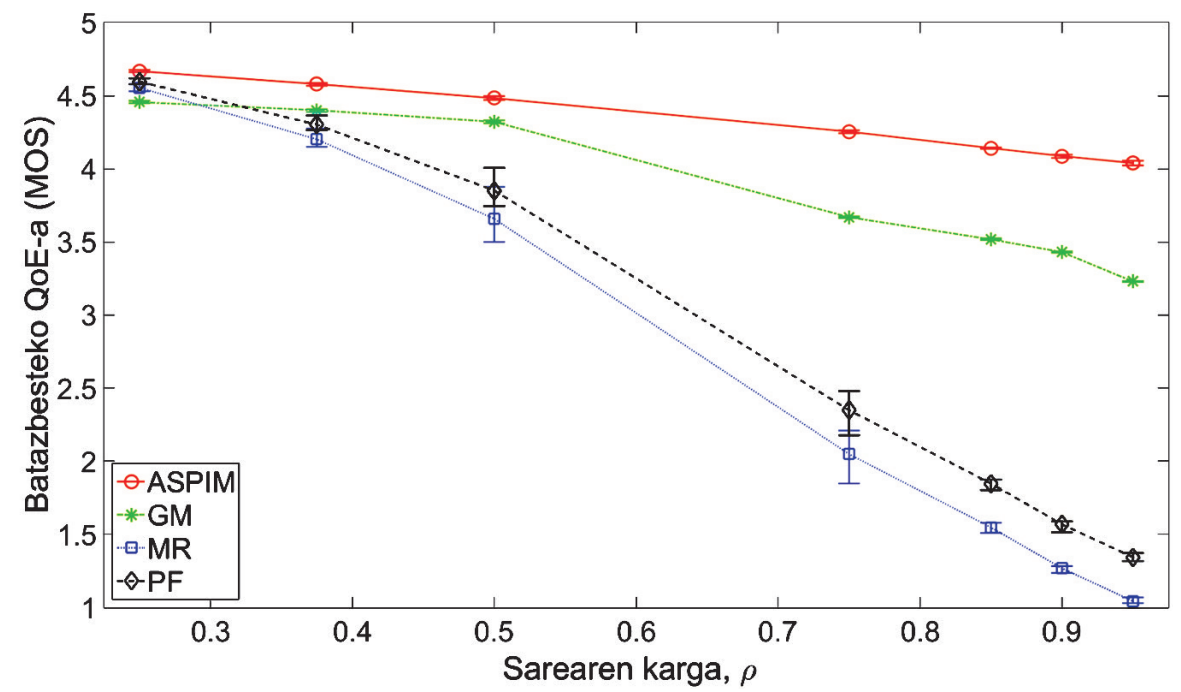

1. irudia. Batez besteko QoE-aren emaitzak.

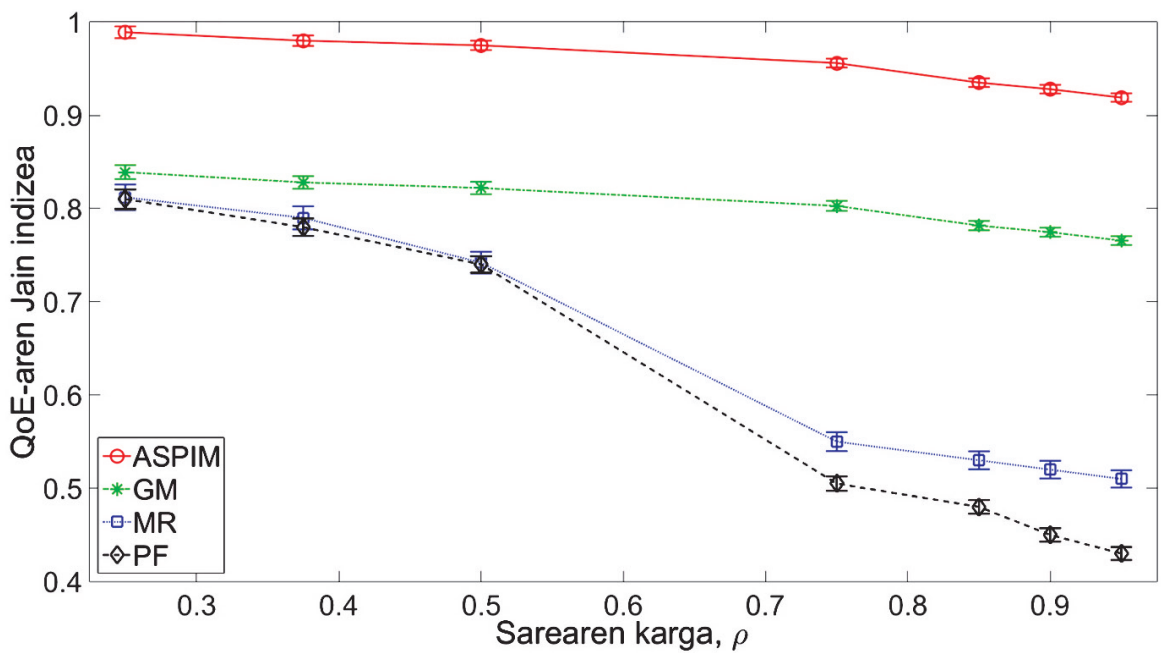

2. irudia. QoE-aren ekitatearen emaitzak: MOS-aren Jain indizea.

\section{ONDORIOAK}

Lan honetan QoE-aren optimizaziorako proposatuko GM eta ASPIM planifikazio indize-erregelak konparatzeari ekin zaio. Horretarako, lehenik 
eta behin, bi QoE-aware planifikazio politika horiek aurkeztu dira, eta ondoren, horien errendimendua analizatu da.

Egindako errendimenduaren azterketaren arabera, batez besteko QoEari dagokionez, ASPIM izan ezik, GM-ek gainontzeko diziplina guztiak gainditzen ditu, biak gogobetetze-atalasearen $(\mathrm{MOS}=3)$ gainetik mantentzen direlarik. Gainera, ASPIM-en eta GM-en arteko aldea kasurik txarrenean 1 ingurukoa da. QoE-aren ekitateari erreferentzia eginez, bi diziplinen Jain indizeen arteko diferentzia kasurik txarrenean 0,15 ingurukoa da. Horretaz gain aparte, GM-ek PF eta MR beti nabarmenki irabazten ditu.

Beraz, esan daiteke GM dela bigarren aukerarik onena QoE-an, eta antza denez, bi QoE-aware politiken QoE metriken aldea ikusita, atzerapenaren menpekoa den MOS funtzio horren eragina batez besteko MOS-ean oso altua da, ASPIM-en azaltzen diren kanal-egoera probabilitateek baino pisu gehiago duelarik.

Aitzitik, ASPIM indize-erregela GM indize-erregela baino konplexuagoa da, GM-en inplementazioa errazagoa zein exekuzio-denbora azkarragoa direlarik. Batetik, GM indize-erregela berehalakoa da, hau da, ASPIM-en ez bezala, indizeen kalkulurako ez da erregelaren kanal-egoera onenerako baldintzarik egiaztatzen. Simulazioetan behatzen denaren arabera, exekuzio-denborari dagokionez, GM ASPIM baino 16 aldiz arinagoa da gutxi gorabehera.

Bestetik, GM-en kasuan indize bakoitzaren bukatze-probabilitate hobekuntzarako batukaririk ez da erabiltzen. Horrez gain, ASPIM indizearen kalkulurako kanal-egoera probabilitateak behar izateak aldez aurretik kanala modelaturik egotea eskatzen du.

Hortaz, lortu nahi den QoE-aren maximizazioaren zehaztasunaren eta indize-erregelaren konplexutasunaren arteko oreka bilatuko da ASPIM edo GM aukeratzerakoan.

\section{ESKER ONAK}

Artikulu honek Espainiako Ekonomia eta Lehiakortasun Ministerioaren (MINECO) diru-laguntza jaso du, TEC2013-46766-R: QoEverage-«QoEaware optimization mechanisms for next generation networks and services» proiektuaren bidez.

\section{BIBLIOGRAFIA}

[1] 3GPP. 2010. «TS-123107 v9.0.0. Quality of Service (QoS) concept and architecture». 
[2] ITU-T. 2004. «Quality of Service and network performance».

[3] PUTERMAN M.L. 1990. «Markov decision processes». Handbooks in Operations Research and Management Science, 2, 331-434.

[4] AL-ZUBAIDY H., LAMBADARIS I. eta VINIOTIS Y. 2012. «Optimal scheduling in multi-server queues with random connectivity and retransmissions». Computer Communications, 35, 1626-1638.

[5] PAPADIMITRIOU C.H. eta TSITSIKLIS J.N. 1987. «The complexity of Markov decision processes». Mathematics of operations research, 12, 441450.

[6] CHEN H., CHENG C.C., CHUNG W.H. eta YEH H.H. 2012. «A reduced dimension MDP-based call admission control scheme for next generation telecommunications». Wireless Communications and Mobile Computing Conference (IWCMC), 984-989.

[7] BOLIA N. eta KULKARNI V. 2009. «Index policies for resource allocation in wireless networks». IEEE Transactions on Vehicular Technology, 58, 1823-1835.

[8] JACKO P. 2011. «Optimal index rules for single resource allocation to stochastic dynamic competitors». In Proceedings of the 5th International ICST Conference on Performance Evaluation Methodologies and Tools, 425-433.

[9] KLEINROCK L. 1976. Queueing Systems. Volume 2: Computer Applications. John Wiley\&Sons.

[10] AVRACHENKOVT K., AYESTA U., BROWN P. eta NYBERG E. 2004. «Differentiation between short and long TCP flows: Predictability of the response time». IEEE INFOCOM, 2, 762-773.

[11] AALTO S. eta AYESTA U. 2008. «Optimal scheduling of jobs with a DHR tail in the M/G/1 queue». Proceedings of the 3rd International Conference on Performance Evaluation Methodologies and Tools, 50.

[12] GITTINS J.C. 1979. «Bandit processes and dynamic allocation indices». Journal of the Royal Statistical Society. Series B (Methodological), 148-177.

[13] AALTO S., AYESTA U. eta RIGHTER R. 2011. «Properties of the Gittins index with application to optimal scheduling». Probability in the Engineering and Informational Sciences, 25, 69-288.

[14] ASADI A. eta MANCUSO V. 2013. «A Survey on Opportunistic Scheduling in Wireless Communications». IEEE Communications Surveys \& Tutorials, 15, 1671-1688.

[15] AALTO S. eta LASSILA P. 2010. «Flow-level stability and performance of channel-aware priority-based schedulers». IEEE Next Generation Internet (NGI), 1-8.

[16] AYESTA U., ERAUSQUIN M. eta JACKO P. 2010. «A modeling framework for optimizing the flow-level scheduling with time-varying channels». Performance Evaluation, 67, 1014-1029.

[17] TABOADA I., JACKO P., AYESTA U. eta LIBERAL F. 2014. «Opportunistic Scheduling of Flows with General Size Distribution in Wireless TimeVarying Channels». 26th International Teletraffic Conference (ITC). 
[18] TABOADA I., LIBERAL F. eta JACKO P. 2014. "An Opportunistic and Non-Anticipating Size-Aware Scheduling Proposal for Mean Holding Cost Minimization in Time-Varying Channels». Performance Evaluation, 79, 90103.

[19] WHITTLE P. 1988. «Restless bandits: Activity allocation in a changing world». A Celebration of Applied Probability, J. Gani (Ed.), Journal of Applied Probability, 25A, 287-298.

[20] GITTINS J., GLAZEBROOK K. eta WEBER R. 2011. Multi-armed bandit allocation indices. John Wiley \& Sons.

[21] ITU-T. 2007. «P.10/G.100 (2006) Amendment 1 (01/07): New Appendix I definition of Quality of Experience (QoE)».

[22] TABOADA I., LIBERAL F., FAJARDO J.O. eta AYESTA U. 2013. «QoEaware optimization of multimedia flow scheduling». Computer Communications, 36, 1629-1638.

[23] TABOADA I. eta LIBERAL F. 2014. «A Novel Scheduling Index Rule Proposal for QoE Maximization in Wireless Networks», Abstract and Applied Analysis, 2014.

[24] WIERMAN A. 2011. «Fairness and scheduling in single server queues». Surveys in Operations Research and Management Science, 16, 39-48.

[25] BERGSTRA J.A. eta MIDDELBURG C.A. 2003. «ITU-T Recommendation G. 107: The E-Model, a computational model for use in transmission planning».

[26] FIEDLER M., HOSSFELD T. eta TRAN-GIA P. 2010. «A generic quantitative relationship between Quality of Experience and Quality of Service». IEEE Network, 24, 36-41.

[27] IKUNO J.C., WRULICH M. eta RUPP M. 2010. «System level simulation of LTE networks». IEEE 71 st Vehicular Technology Conference.

[28] JAIN R., D. CHIU D. eta HAWE W.R. 1984. «A quantitative measure of fairness and discrimination for resource allocation in shared computer system». Eastern Research Laboratory, Digital Equipment Corporation. 